\title{
Weakening Organizational Ties? A Classification of Styles of Volunteering in the Flemish Red Cross
}

\author{
Lesley Hustinx \\ Katholieke Universiteit Leuven
}

This article presents an initial empirical assessment of a new analytical framework of styles of volunteering (SOV). The framework suggests that volunteering can be categorized in terms of a multidimensional set of cultural and structural indicators that cohere in systematic and varying ways. With data drawn from a survey of 652 Flemish Red Cross volunteers, a multivariate analysis reveals five different SOV categories of volunteers: episodic contributors, established administrators, reliable coworkers, service-oriented core volunteers, and critical key figures. The research findings indicate that the volunteer reality is far more complex than suggested by conventional approaches to the study of volunteering.

One of the quintessential relationships in the nonprofit field is that between organizations and their volunteers. Volunteers are crucial resources, providing many nonprofit organizations with free time, labor, and skills. There recently has been a growing conviction among scholars and practitioners that a major shift is taking place toward new modes of volunteer participation. It frequently is suggested that the new modes fall short of the type and degree of commitment that the average organization needs. In the wake of broader modernization and individualization processes, the basic trend appears to be one toward loosening connections (Wuthnow 1998): more individual, short-lived, noncommittal, and highly results-oriented volunteer involvement (see, e.g., Jakob 1993; Voyé 1995; Bennett 1998; Gaskin 1998; Klages 1998; Anheier and Salamon 1999; Kühnlein and Mutz 1999; Beher, Liebig, and Rauschenbach 2000; Brömme and Strasser

Social Service Review (December 2005).

(c) 2005 by The University of Chicago. All rights reserved.

0037-7961/2005/7904-0003\$10.00 
2001; Eckstein 2001; Meijs and Hoogstad 2001; Hacket and Mutz 2002; Inglehart 2003; Macduff 2004a; Stolle and Hooghe 2005). Rather than carrying out activities as a mere function of membership affiliations and fidelity to the organization, volunteers allegedly want to choose à la carte what and at what times they contribute (Wollebæk and Selle 2003, 162). The heralded transition from strong and durable membership affiliations to weak and temporary ones has provoked an imaginative series of new expressions, such as the shrinking volunteer, the revolving-door volunteer, episodic volunteering, and vicarious commitments (see, e.g., Maloney and Jordan 1997; Dekker and Halman 2003; Macduff 2004a, 2004b, 2005; Cnaan and Handy 2005).

Although the empirical tenability of these popular terms has yet to be verified, the idea of changing modes of involvement poses fundamental challenges to scholarly research on volunteering. Despite the widely held opinion that the nature of volunteering is undergoing a profound transformation, scholars in the field still have to provide the analytical tools and empirical data warranted by the changing modes of volunteer involvement. As Dietlind Stolle and Marc Hooghe observe, "Systematic evidence on the new forms of involvement has yet to be collected, and thus studies in this field are often anecdotal in nature" (2005, 159; cf. Anheier and Salamon 1999, 55).

A profound understanding of the exact nature and complexity of the changes in volunteering is obstructed by both theoretical and methodological deficits. At the theoretical level, accounts of the ongoing shift typically represent what Jone Pearce (1993) describes as a bifurcated volunteer reality. Pearce's original distinction between core and peripheral volunteers is now supplemented with dichotomies between old or traditional and new or modern (Olk 1989; Jakob 1993; Rommel et al. 1997; Kühnlein 1998), collectivistic and individualistic (Eckstein 2001), membership-based and program-based (Meijs and Hoogstad 2001), or institutionalized and self-organized (Beck 1997; Brömme and Strasser 2001) participation.

Although a plurality of modes of involvement is assumed to exist among these opposing representations, the two-term typologies are not very nuanced. Theoretically, it is not obvious that there are simple distinctions between traditional or old and modern or new. So too, it is unclear whether a coherence with which interrelations are drawn between a multidimensional series of (changing) volunteer features finds its reflection in a comparably clear-cut and coherent volunteer reality. The ongoing debate automatically matches a broad amalgam of typically new volunteer characteristics, equating short-term involvement, detached attitudes, noncommittal manner, opportunistic behavior, selfcentered conduct, and other qualities. The empirical validity of these seemingly self-evident equations, however, remains unestablished.

Empirical research on volunteering typically takes an approach di- 
rected toward uniformity. The term "volunteering" is used as a catchall for a wide variety of types and modes of participation or else is reduced to one of its multiple dimensions (Cnaan and Amrofell 1994; Cnaan, Handy, and Wadsworth 1996; Handy et al. 2000). Empirical studies of volunteering are preoccupied with either assessing levels of volunteering in general or explaining separate subdimensions of volunteering (pars pro toto). Systematic scholarly attention thus has been paid to the implications of different survey methodologies for reported levels of giving and volunteering (see, e.g., Hall 2001; Kennedy and Vargus 2001; O’Neill 2001; Steinberg, Rooney, and Chin 2002; Rooney, Steinberg, and Schervisch 2004), while a vast stream of research also explores variations in volunteering in terms of disconnected subdimensions: attachment to volunteering, the length of volunteer service, volunteer retention, motivation to volunteer, intensity of volunteering, volunteer performance, and so on (see, e.g., Sundeen 1990; Sokolowski 1996; Wilson and Musick 1997, 1999; Janoski, Musick, and Wilson 1998; Penner and Finkelstein 1998; Farmer and Fedor 1999; Grube and Piliavin 2000; Putnam 2000). In both research approaches, the standardized understanding of volunteering typically results in the use of a unidimensional dependent variable: one either predicts volunteer participation in general (yes or no), as if it were a uniform entity, or one constructs explanatory models for detached subcomponents, not taking into account how these disconnected volunteer features are tied up with the encompassing volunteer reality. In any case, the multifaceted nature of volunteering is simply reduced to a single, consistent measure.

A more fine-grained type of empirical analysis is required to grasp the multifaceted and presumably changing nature of volunteering. The remainder of this article therefore seeks to advance a new and more complex way of measuring the interplay among the various dimensions and characteristics of volunteer participation. This new research approach should result in a more in-depth and multidimensional consideration of the nature of volunteering. Although this article only presents an initial empirical impetus to more complex ways of measuring volunteering, the approach has the potential of accurately mapping trends in modes of participation across different types of organizations and over time.

\section{The SOV Construct: A New Analytical Framework}

In order to seek a profound understanding of the varied nature of volunteer participation, this work advances an analytical framework to identify styles of volunteering (SOV). The proposed framework could enable research to advance beyond current uniform and unidimensional approaches by analyzing systematically and simultaneously multiple indicators of volunteering. 


\section{Context of Volunteering}

First, in the exploration of the changing nature of volunteer involvement, a distinction is made between structural change in modes of volunteering and cultural shifts in the ethos of the volunteers, that is, in their values, perceptions, beliefs, and attitudes (see, e.g., Barker 1993; Dekker and Halman 2003; Inglehart 2003; Reed and Selbee 2003). According to Karin Beher and associates (2000, 8-10), the structural context of volunteering consists both of the individual life situation, or the subject-relevant reflection of social structures and relations, and of the organizational settings in which volunteer action takes place. Ideally, the assumed restructuring of volunteering also has to be analyzed against the background of larger institutional and ideological contexts (cf. Salamon and Anheier 1998; Curtis, Baer, and Grabb 2001; Schofer and Fourcade-Gourinchas 2001; Salamon and Sokolowski 2003). The cultural context is represented by the attitudinal and motivational bases of volunteering, that is, volunteers' subjective preferences. This context involves the heralded shift in the commitment of the volunteers toward the organization and their volunteer tasks. It is represented by their changing preferences as well as by their demands for a greater freedom of choice and more opportunities for self-realization.

\section{The Multidimensionality Criterion}

The multidimensionality criterion suggests that a multidimensional set of interrelated changes is occurring in structure and culture. For example, short-term types of involvement may cohere with limited job responsibilities and restricted time investment. The high levels of selforientation among volunteers may be intertwined with a strong preference for tangible goals, a weak service ethic, and an uncertain sense of obligation to the organization or community. This multidimensionality should be reflected in both the structural and the cultural contexts. Previous work discusses these dimensions (see Hustinx 2003; Hustinx and Lammertyn 2003, 2004; cf. Jakob 1993; Rommel et al. 1997; Kühnlein 1998), as reported below.

\section{The Multiformity Criterion}

The multiformity criterion follows logically from the specified need for a more differentiated understanding of the existing volunteer diversity. It suggests that a SOV typology can be developed across the structural and cultural dimensions. The multiformity criterion is based on the assumption that the behavioral and attitudinal levels of analysis, as well as the various subdimensions discussed above, intertwine in systematic ways. The exact styles of volunteering that evolve from this interplay should be explored empirically in a concrete volunteer setting. The 
assumption of multiformity as a formal SOV criterion should compel a more purposive and rigorous investigation into the complexity of styles of volunteering. It should lead beyond the usual monolithic and bifurcated approaches to the study of volunteering.

\section{Research Methods}

To explore these assumptions empirically, two main analytical steps are required. The first investigates whether it is possible to group the sample of volunteers according to the measure of structure and culture used here. Much of this work was accomplished in previous publications. The second examines whether the structural and cultural SOV components, as hypothesized, interrelate in systematic ways. In other words, does the theoretical supposition hold that volunteer attitudes and behavior are intertwined parts of the same construct? What kind of style variations emerge from the analysis, and how do they relate to the theoretically conceived bifurcated volunteer reality?

Given the complex, multivariate nature of this analytical framework, a combination of data reduction, classification, and visualization techniques is applied. In the limited space of this article, assessment will be focused on the cultural SOV component and on the coordinating SOV construct. The analysis of the structural SOV component is similar to that of styles of volunteering in general (for a detailed description of the structural bases of volunteering, see Hustinx 2003, 223-32).

\section{Sample and Data Collection}

Data used in this study are drawn from a survey that consisted of 652 personal in-home interviews with a representative sample of volunteers from five Flemish Red Cross units: the First Aid Unit, the Red Cross Youth, the Social Services Unit, the Training Unit, and the Unit for Psycho-Social Intervention in Disasters. These specific units were chosen, in consultation with some key informants within the Flemish Red Cross, out of a wide variety of services. The consultations were undertaken to ensure a maximum variety of volunteer profiles. ${ }^{1}$ The respondents were selected from central volunteer records on the basis of a multistage sampling procedure. In a first step, the sample was geographically limited by means of a random selection of 50 local branches of the Flemish Red Cross (equally spread over the five Flemish provinces). Within these Red Cross chapters, a disproportional sample of volunteers was subsequently subtracted from the five selected units, underrepresenting units with large numbers of volunteers and overrepresenting units with small numbers of volunteers (for a detailed discussion, see Hustinx 2003, 120-24).

All volunteers in the sample were interviewed using a standardized face- 
to-face questionnaire in the spring of 2000. In dividing the number of complete interviews by the number of potential respondents, a response rate of 79 percent is obtained (the American Association for Public Opinion Research's [AAPOR] minimum response rate; see AAPOR 2005, 28). This relatively low response rate mainly results from a large proportion of noncontacts (18 percent of the total number of contacts with potential respondents). Explicit refusals occurred in 2 percent of all contacts with potential respondents. Nonresponders (i.e., all eligible cases for which no interview was obtained owing to refusals or break offs, noncontacts, or other reasons; AAPOR 2005, 18-19) did not systematically differ from responders with regard to sex, age, and length of service. The age and gender characteristics of the sample proved to be representative of the volunteer population studied. However, the length of service among the selected volunteers differed from the volunteer population as a whole and therefore appeared to be an inaccurate representation of the real population distribution. To remedy this, weight factors were introduced for age and length of service for each selected Red Cross unit separately (for a discussion, see Hustinx 2003, 127-33).

Of the respondents, 51 percent were male and 49 percent were female. The age of the volunteers ranged from 15 to 81 years, with a mean of 36 years and a median of 35 years. Twenty-five percent were younger than 24 years, and only 10 percent were older than 57 years. Twenty-nine percent of the sample had an educational level not exceeding lower secondary school, 38 percent had completed their higher secondary education, and 33 percent had some form of higher education. ${ }^{2}$ The respondents predominantly lived with a spouse (51 percent), with parents, or with other family members (33 percent). Alternative living arrangements, like cohabitation ( 7 percent) or living alone (9 percent), were less frequent. Four out of 10 respondents had children in the household. Forty-eight percent of the respondents were employed full-time, 10 percent had a part-time job, and 14 percent were unemployed, incapacitated, or housekeepers. Retirees and students represented, respectively, 8 percent and 20 percent of the sample. At the time of the survey, the responding volunteers reported that they served the Flemish Red Cross for an average of 8 years. Half of the volunteers served for more than 5 years, one out of four for even more than 10 years. Thirty-one percent of the sample had a length of service of 3 years or less.

\section{Measures}

Structural indicators of styles of volunteering.-The phrase "patterns of volunteering" refers to the structural aspects of volunteering and represents multiple dimensions (Hustinx and Lammertyn 2003). For the purposes of this analysis, these patterns include the length of service, 
the intensity of involvement, and the particular choice of action (core or peripheral). ${ }^{3}$ The volunteers' length of service is measured in years. ${ }^{4}$ The intensity of involvement is measured by the frequency of volunteering (categories ranging from daily to once a year) and the amount of time invested in the volunteer commitment (estimation in hours per month or per year). The choice of action is captured by two measures of the extent to which the volunteers occupy a core or peripheral position. One is whether volunteers hold formal office on a volunteer board. The second is the number of main activities the volunteers reportedly performed in different Red Cross units. The multivariate classification thus does not account for the precise nature of the volunteer activities.

Cultural indicators of styles of volunteering.-To measure the cultural dimensions of the styles of volunteering, previous research (Hustinx 2003; Hustinx and Lammertyn 2004) developed variables in several steps. First, an exploratory factor analysis was conducted to construct a multidimensional set of attitudinal volunteer measures (Rummel 1970; Kim and Mueller 1978a, 1978b; Gorsuch 1983).$^{5}$ Eleven common factors were obtained and regrouped into four broad attitudinal-motivational dimensions: (1) the volunteer's perception of the organizational environment: the volunteer's evaluation of the mission of the organization and the perceived level of bureaucracy; (2) the motives for volunteering: the importance that the volunteer attaches to recognition, satisfaction, and self-development derived through volunteering; (3) the volunteer's commitment to organization and volunteer work: the degree of loyalty, devotion, and choosiness of the volunteers, as well as their preference for a low-level commitment; (4) the volunteer's tolerance toward organizational demands: tolerance toward training demands and toward rules concerning the intensity of commitment.

Next, 11 factor-based scale scores are created by adding together participants' responses concerning the items with high loadings on the retained factors. The appendix presents an overview of the selected items per scale.

Finally, because the author hypothesizes that the 11 attitudinal scales constructed are subdimensions of the broader culture-of-the-volunteer concept, these measures were combined into a more limited number of cultural volunteer profiles (for a detailed discussion of this empirical assessment of the cultural bases of volunteering, see Hustinx 2003; Hustinx and Lammertyn 2004). To disclose these varying cultural positions, the multidimensional set of Likert scales was subjected to an exploratory cluster analysis (Ward's minimum variance method; Aldenderfer and Blashfield 1984; Everitt 1993). A four-cluster solution was obtained. ${ }^{6}$ The cluster means on the attitudinal measures are shown in table 1 . These mean scores can be compared to interpret the main differences among the clusters. It should be emphasized that 
Table 1

Descriptive Statistics of the Factor-Based Scales and Cultural Volunteer Clusters

\begin{tabular}{|c|c|c|c|c|c|c|c|c|c|c|}
\hline VARIABLE & $\begin{array}{l}\text { Number } \\
\text { OF ItEms }\end{array}$ & $\begin{array}{c}\text { Cronbach's } \\
\alpha\end{array}$ & $\begin{array}{l}\text { Minimum- } \\
\text { Maximum } \\
\text { RANGE }\end{array}$ & $\begin{array}{l}\text { GENERAL } \\
\text { MEAN }\end{array}$ & SD & \multicolumn{5}{|c|}{ Cluuster } \\
\hline \multicolumn{11}{|l|}{ Volunteers' perception of organization environment: } \\
\hline Perceived level of bureaucracy & 7 & .80 & $1-7$ & 3.2 & 1.1 & $2.4^{\mathrm{a}}$ & $4.1^{\mathrm{b}}$ & $2.9^{c}$ & $3.8^{\mathrm{d}}$ & .41 \\
\hline \multicolumn{11}{|l|}{ Motives for volunteering: } \\
\hline Recognition & 6 & .78 & $1-5$ & 2.8 & .86 & $3.5^{\mathrm{a}}$ & $2.9^{\mathrm{b}}$ & $2.5^{\mathrm{c}}$ & $2.5^{c}$ & .26 \\
\hline Satisfaction & 6 & .78 & $1-5$ & 4.0 & .69 & $4.5^{\mathrm{a}}$ & $4.1^{\mathrm{b}}$ & $3.8^{\mathrm{c}}$ & $3.6^{\mathrm{d}}$ & .25 \\
\hline Loyalty & 6 & .77 & $1-5$ & 3.7 & .77 & $4.2^{\mathrm{a}}$ & $3.8^{\mathrm{b}}$ & $3.4^{\mathrm{c}}$ & $3.2^{c}$ & .26 \\
\hline Devotion & 3 & .67 & $1-7$ & 5.8 & 1.1 & $6.5^{\mathrm{a}}$ & $5.9^{\mathrm{b}}$ & $5.8^{\mathrm{b}}$ & $4.2^{c}$ & .52 \\
\hline Choosiness & 5 & .62 & $1-5$ & 3.2 & .79 & $2.7^{\mathrm{a}}$ & $3.1^{\mathrm{b}}$ & $3.3^{\mathrm{b}}$ & $3.5^{\mathrm{c}}$ & .13 \\
\hline Preference for a low-level commitment & 6 & .62 & $1-7$ & 3.7 & .91 & $3.3^{\mathrm{a}}$ & $3.5^{\mathrm{a}}$ & $4.0^{\mathrm{b}}$ & $3.9^{\mathrm{b}}$ & .10 \\
\hline \multicolumn{11}{|l|}{ Tolerance toward organizational demands: } \\
\hline Training demands & 5 & .71 & $1-5$ & 4.4 & .68 & $4.6^{\mathrm{a}}$ & $4.4^{\mathrm{b}}$ & $4.4^{\mathrm{b}}$ & $4.2^{\mathrm{b}}$ & .03 \\
\hline Rules concerning the intensity of commitment & 4 & .69 & $1-5$ & 2.1 & .87 & $2.3^{\mathrm{a}}$ & $2.1^{\mathrm{b}}$ & $2.0^{\mathrm{b}}$ & $2.3^{\mathrm{a}}$ & .03 \\
\hline Percent of total $(N=622)$ & & & & & & 25.9 & 21.7 & 34.8 & 17.6 & \\
\hline
\end{tabular}

NoтE.-A high score reflects a strong positive attitude toward the latent factor. Superscripts a, b, c, and d display the results of a Tukey's Honestly Significant Difference (or HSD) test for multiple comparisons between pairs of mean scores (Hair et al. 1995, 282). If two mean scores have the same superscript, no significant difference exists among them at the .05 significance level. If two mean scores have a different superscript, a significant difference exists among them at the .05 significance level. Four different superscripts thus indicate that the Tukey's HSD test revealed significant differences for all pairwise comparisons of the four mean scores. This table was originally published in Nonprofit Voluntary Sector Quarterly (33, no. 4 [2004]: 564). Adapted with permission from the author.

* Overall $R^{2}=.23$; all ANOVA tests are significant at the .001 level 
these mean differences are compared only for descriptive purposes, since statistically significant differences cannot serve as a guarantee for the quality of the cluster solution. ${ }^{7}$

If one draws a general picture from these mean differences, the cultural bases of volunteering could be broadly interpreted along the lines of two axes. On the one hand, the clusters can be distinguished according to the strength of the general identification with or the commitment to the organization and volunteer engagement (indicators are the factors mission of the organization, perceived level of bureaucracy, recognition, satisfaction, self-development, loyalty, and devotion). On the other hand, the volunteer cultures differ according to the extent to which the individual subordinates himself or herself to organizational demands or puts personal needs and preferences first (indicators are the factors choosiness, preference for a low-level commitment, tolerance of training demands, and tolerance of rules concerning the intensity of commitment). The first cluster reflects a very strong identification with and subordination to the organization and volunteer experience. Compared to respondents in the other clusters, volunteers represented by this cluster appear to be substantially more loyal, more devoted, and less choosy. They do not eschew demanding forms of commitment. They are more motivated than other respondents by a desire for social recognition and derive more satisfaction from belonging to a volunteer group. They attach significantly greater value to the organization's mission and are less critical of bureaucratic tendencies. Compared to respondents in the other clusters, they are also more willing to accept rules concerning the intensity of the commitment. Like those in the first cluster, the volunteers in the second group also display high levels of identification and subordination. Their most characteristic property is the critical evaluation of bureaucratic tendencies in the Red Cross. The third cluster includes volunteers who only moderately identify with the Red Cross involvement. Members are not particularly inclined to set aside their individual preferences for the sake of the organization. However, the volunteers' level of devotion still is high. The volunteers of the fourth cluster largely are characterized by their remarkably weak commitment to the organization and volunteer work, as well as by a low willingness to subordinate individual to organizational demands and needs. The names of these clusters refer to their most distinguishing dispositional characteristics; they are labeled as unconditional (cluster 1), critical (cluster 2), reliable (cluster 3), and distant (cluster 4). To test the validity of the results of a cluster analysis, an external criterion analysis (Aldenderfer and Blashfield 1984, 66, 81) was completed by comparing the clusters according to a number of external variables that were not included in the cluster analysis (see Hustinx 2003, 220-23; Hustinx and Lammertyn 2004, 566-68). 


\section{Data Analysis}

The main purpose of this article is to investigate whether the cultural volunteer clusters and structural volunteer measures are components of a common and underlying SOV complex. This requires construction of a single behavioral-dispositional measure for the general SOV construct. Such a measure will tap the interplay between cultural and structural substrata. Because the variables generally are categorical (manifest and latent), latent class analysis (LCA) is used for data reduction (McCutcheon 1987, 1994, 2002; Hagenaars 1993). By means of LCA, it is possible to examine whether some lesser number of categories might account for the observed response patterns. More concretely, LCA uses information from categorically scored manifest (observed) indicator variables to characterize a single latent (unobserved) variable with $T$ classes. These classes are mutually exclusive and exhaustive. They account for the relationship between any two manifest variables (i.e., the axiom of local independence; McCutcheon 1994, $354 ; 2002,58)$. For the research at issue, LCA is used as an exploratory method. A set of latent classes is identified from a set of observed measures, but hypotheses regarding the characteristics of the conditional or latent class probabilities are not tested. The latent class model is said to be unrestricted in exploratory latent class analysis, since no a priori constraints are imposed on either type of the model's parameters (McCutcheon 1987, 27-28). The LEM program is used in order to derive a latent class model from the observed measures. This is a general system for the analysis of nominal-, ordinal-, and interval-level categorical data (Vermunt 1997). Among other things, it can be used to obtain parameter estimates for latent structure models that are based on categorical data.

The latent class model is based on a cross-classification of the clustered cultural measure and the five key structural indicators. The model results from a contingency table with 288 possible response patterns that were reduced to five latent classes $\left(L^{2}=251.17, \mathrm{df}=233, p=0.19\right)$. This reduction confirms that the association among the manifest variables is explained by their relationship with an underlying common construct. Table 2 reports the parameter estimates of the model. These estimates express the differential contribution of each of the five latent classes to the cross-classified observed SOV measures. ${ }^{8}$

Whereas the original latent class model in table 2 is based on probabilities, a more detailed interpretation is sought by assigning observations to that latent class for which the estimated classification probability is largest, given the scores on the manifest variables (i.e., the modal assignment rule; Hagenaars 1993, 32-34). These proportional distributions form the basis for figure 1 and table 3, which display the classes across an extended set of indicators. Figure 1 divides the variables 
Table 2

Parameter Estimates of the Latent Class Model

\begin{tabular}{|c|c|c|c|c|c|c|c|c|c|c|}
\hline & \multicolumn{5}{|c|}{$\begin{array}{c}\text { PatTERnS OF } \\
\text { VOLUNTEERING }\end{array}$} & \multicolumn{5}{|c|}{ Styles of VolunteEering } \\
\hline & I & II & III & IV & $\mathrm{V}$ & $\mathrm{I}$ & II & III & IV & $\mathrm{V}$ \\
\hline $\begin{array}{l}\text { Latent class probabilities } \\
\text { Latent conditional probabil- } \\
\text { ities: }\end{array}$ & .24 & .11 & .22 & .31 & .11 & .23 & .12 & .19 & .29 & .17 \\
\hline \multicolumn{11}{|l|}{ Structural dimensions: } \\
\hline $0-5$ years & .55 & .19 & .61 & .47 & .00 & .53 & .25 & .58 & .53 & .11 \\
\hline$>5$ years & .45 & .81 & .39 & .53 & 1.00 & .47 & .75 & .42 & .47 & .89 \\
\hline \multicolumn{11}{|l|}{ Frequency: } \\
\hline $\begin{array}{c}\text { Once or several } \\
\text { times a year } \\
\text { Once or several }\end{array}$ & .90 & .27 & .00 & .02 & .01 & .94 & .22 & .00 & .04 & .00 \\
\hline times a month & .10 & .50 & 1.00 & .21 & .06 & .00 & .48 & 1.00 & .43 & .03 \\
\hline Weekly or more & .00 & .23 & .00 & .77 & .93 & .06 & .30 & .00 & .53 & .97 \\
\hline \multicolumn{11}{|l|}{ Hours of volunteering: } \\
\hline $\begin{array}{l}\text { 0-12 hours per } \\
\text { month } \\
>12 \text { hours per }\end{array}$ & .96 & 1.00 & .71 & .10 & .01 & 1.00 & .99 & 1.00 & .00 & .00 \\
\hline $\begin{array}{l}\text { month } \\
\text { Member of volunteer } \\
\text { board: }\end{array}$ & .04 & .00 & .29 & .90 & .99 & .00 & .01 & .00 & 1.00 & 1.00 \\
\hline No & 1.00 & .33 & .94 & .65 & .01 & 1.00 & .23 & .97 & .79 & .11 \\
\hline Yes & .00 & .67 & .06 & .35 & .99 & .00 & .77 & .03 & .21 & .89 \\
\hline \multicolumn{11}{|l|}{$\begin{array}{l}\text { Number of main activi- } \\
\text { ties: }\end{array}$} \\
\hline None & .40 & .52 & .10 & .08 & .18 & .39 & 42 & .16 & .10 & .14 \\
\hline One & .46 & .32 & .63 & .64 & .35 & .47 & .39 & .61 & .63 & .43 \\
\hline More than one & .14 & .16 & .27 & .28 & .47 & .14 & .19 & .23 & .27 & .43 \\
\hline $\begin{array}{l}\text { Cultural dimensions (cul- } \\
\text { tural volunteer } \\
\text { clusters): }\end{array}$ & & & & & & & & & & \\
\hline Unconditional & & & & & & .07 & 17 & .23 & .35 & .32 \\
\hline Critical & & & & & & .11 & .28 & .16 & .20 & .45 \\
\hline Reliable & & & & & & .45 & .25 & .42 & .29 & .13 \\
\hline Distant & & & & & & .37 & .30 & .19 & .16 & .10 \\
\hline
\end{tabular}

Note.-Latent class probabilities describe the distribution of classes of the latent variable; latent conditional probabilities represent the probabilities of an individual in class $T$ of the latent variable being at a particular level of the observed variables (McCutcheon 1987, 18-19). Patterns of volunteering: $N=652, L^{2}=43.39$, df $=32, p=.086, \mathrm{E}=$ $0.172, \lambda=.751 . \mathrm{I}=$ supportive peripheral involvement, $\mathrm{II}=$ administrative intermediate involvement, III = supportive intermediate involvement, IV = supportive core involvement, $\mathrm{V}=$ all-round core involvement. Styles of volunteering: $N=652, L^{2}=251.17$, $\mathrm{df}=233, p=.1972, \mathrm{E}=0.0821, \lambda=.8837 . \mathrm{I}=$ episodic contributors, $\mathrm{II}=$ established administrators, $\mathrm{III}=$ reliable coworkers, $\mathrm{IV}=$ service-oriented core volunteers, $\mathrm{V}=$ critical key figures. 


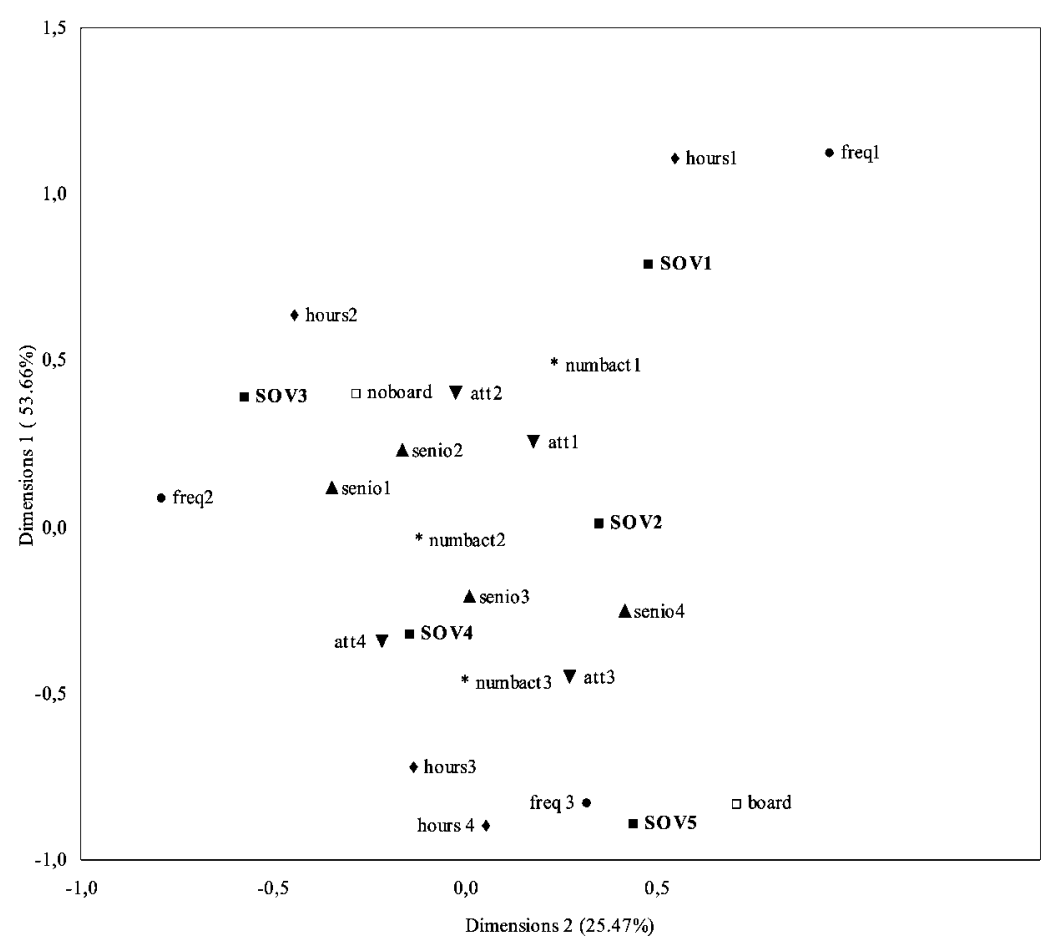

FIG. 1.-Correspondence analysis map for key indicators of styles of Flemish Red Cross volunteering. NOTE.-SOV $=$ styles of volunteering: $\mathrm{SOV} 1=$ first latent style of volunteering class, episodic contributors; SOV2 $=$ second latent style of volunteering class, established administrators; SOV3 = third latent style of volunteering class, reliable coworkers; SOV4 = fourth latent style of volunteering class, service-oriented core volunteers; SOV5 = fifth latent style of volunteering class, critical key figures. Length of service: seniol $=0-2$ years, senio $2=3-5$ years, senio $3=6-10$ years, senio $4=>10$ years. Frequency of volunteering: freq $1=$ once or several times a year; freq $2=$ once or several times a month; freq3 = weekly, or more. Hours of volunteering per month: hours $1=$ $\leq 4$ hours, hours $2=5-12$ hours, hours $3=13-24$ hours, hours $4=>24$ hours. Member of a volunteer board: board $=$ yes, noboard $=$ no. Number of main activities: numbact1 $=$ none, numbact $2=$ one, numbact $3=$ more than one. Cultural volunteer clusters: att 1

$=$ distant, att $2=$ reliable, att $3=$ critical, att $4=$ unconditional.

that were deployed in the exploratory latent class analysis into more detailed categories. Table 3 considers the different types of activities that the volunteers perform. Note that there is a small error margin in the actual assignment of observations to their modal class $(\mathrm{E}=.08$, $\lambda=.88)$.

Figure 1 represents a correspondence analysis that graphically displays the results of the latent class analysis (Greenacre 1994; McCutcheon 1998). ${ }^{9}$ The figure demonstrates that the five styles of volunteering cluster differently with respect to the indicator variables. The first SOV class (SOV1; episodic contributors) appears at the upper right of the space, 
Table 3

Styles of Volunteering according to Key Structural and Cultural Dimensions

\begin{tabular}{|c|c|c|c|c|c|c|}
\hline \multirow[b]{2}{*}{ VARIABLE } & \multicolumn{5}{|c|}{ Styles of Volunteering } & \multirow[b]{2}{*}{ TотаL } \\
\hline & I & II & III & IV & $\mathrm{V}$ & \\
\hline$N(\%)$ & $139(21.32)$ & $58(8.91)$ & $126(19.39)$ & $231(35.37)$ & $98(15.01)$ & $652(100.00)$ \\
\hline \multicolumn{7}{|l|}{ Structural dimensions: } \\
\hline \multicolumn{7}{|l|}{ Length of service (years):*** } \\
\hline $0-2$ & 17.99 & 4.66 & 18.76 & 25.47 & 2.93 & 17.34 \\
\hline $3-5$ & 45.07 & 28.22 & 45.35 & 39.91 & 14.86 & 37.26 \\
\hline $6-10$ & 13.75 & 19.90 & 21.17 & 15.93 & 28.01 & 18.65 \\
\hline$>10$ & 23.19 & 47.22 & 14.72 & 18.69 & 54.21 & 26.75 \\
\hline \multicolumn{7}{|l|}{ Frequency:*** } \\
\hline Once or several times a year & 94.26 & 46.94 & 38.48 & 9.56 & .00 & 24.51 \\
\hline Once or several times a month & .00 & 25.76 & 61.52 & 45.65 & 2.00 & 41.28 \\
\hline Weekly or more & 5.74 & 27.30 & .00 & 44.79 & 98.00 & 34.21 \\
\hline \multicolumn{7}{|l|}{ Hours of volunteering (per month):*** } \\
\hline$\leq 4$ & 78.88 & 30.62 & 26.44 & .00 & .00 & 24.67 \\
\hline $5-12$ & 21.12 & 69.38 & 73.56 & .00 & .00 & 24.95 \\
\hline $13-24$ & .00 & .00 & .00 & 53.77 & 38.28 & 24.76 \\
\hline$>24$ & .00 & .00 & .00 & 46.23 & 61.72 & 25.62 \\
\hline Member of volunteer board $(\%) * * *$ & .00 & 96.57 & .00 & 17.40 & 96.31 & 29.22 \\
\hline
\end{tabular}




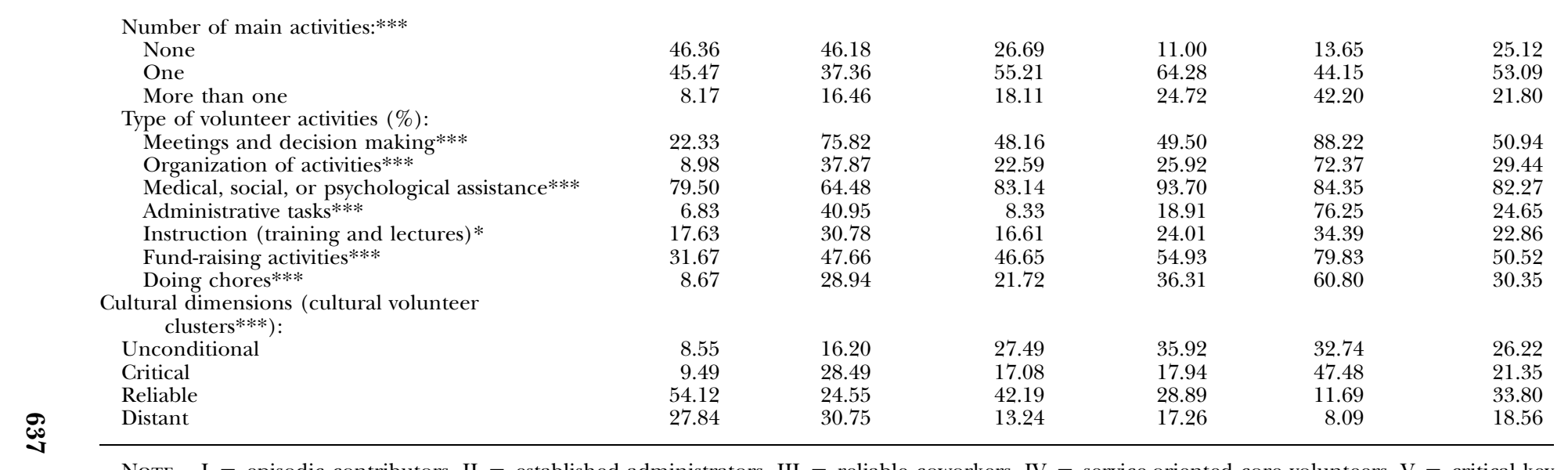

NotE. - I = episodic contributors, II = established administrators, III = reliable coworkers, $\mathrm{IV}=$ service-oriented core volunteers, $\mathrm{V}=$ critical key figures.

* $\chi^{2}$ statistic: $p<.01$.

$* * \chi^{2}$ statistic: $p<.001$
$* * * \chi^{2}$ statistic: $p<.0001$ 
indicating that there are relatively more respondents in this category who volunteer infrequently (freq1; once or several times a year), invest a low amount of time (hours1; four or fewer hours per month), do not perform any main activities (numbact1), and represent a cultural volunteer profile that falls between distant (att1) and reliable (att2). The second class (SOV2; established administrators) is mapped into the center of the figure. This class represents long-term engaged volunteers (senio3, 6-10 years; and senio4, 10 or more years) with a distant (att1) to critical (att3) cultural volunteer profile. The third class (SOV3; reliable coworkers) is positioned in the upper left of the space, indicating volunteers who represent a less intensive mode of involvement. These volunteers seem to take a middle position in their frequency of volunteering and time investment concern (hours2, 5-12 hours; freq2, once or several times a month). They furthermore have been involved for a relatively short period (senio1, 0-2 years; senio2, 3-5 years), have no board memberships (noboard), and represent a reliable cultural volunteer profile (att2). The fourth class (SOV4; service-oriented core volunteers) appears in the lower left quadrant of the figure's field. Volunteers in this class lean toward a stronger involvement. They tend to have an unconditional cultural volunteer profile (att4), long-term service (senio3, 6-10 years; senio4, 10 or more years), and two or more main activities (numbact3). The fifth SOV-class (SOV5, critical key figures) can be found in the lower right of the space, grouping volunteers who are involved very intensively (freq3, weekly or more; hours3, 13-24 hours per month; hours4, more than 24 hours per month), usually hold office in a volunteer board (board), perform several main activities (numbact3), represent a critical cultural volunteer profile (att3), and have a longer length of service (senio4, more than 10 years).

By projecting graphically the relative locations of the indicator variables with respect to the latent classes, it becomes possible to discern and interpret the different types of interrelations for each of the SOV categories in table 3 . The first class of volunteers (SOV1) predominantly represents a group of episodic contributors who volunteer very infrequently (i.e., several times a year at most) and contribute the lowest number of monthly hours among the five volunteer classes. These volunteers clearly operate at the fringes of Red Cross volunteer action. They score remarkably low on all sorts of activities, do not hold office in a volunteer board, and report no more than one main activity. They furthermore identify or affiliate only weakly with the organization or the volunteer experience; that is, they predominantly have a reliable to distant cultural volunteer profile. Despite this remote volunteership, the overall majority of those in this class have been involved for more than 2 years, and more than one-third have served Red Cross Flanders for more than 5 years. This contrasts with the prevailing image of the new 
volunteer generation. Intermittent forms of participation are not necessarily synonymous with short-term or drop-in involvements.

The volunteers of the second class (SOV2) may best be typified as established administrators. Their contribution to the Red Cross remains typically limited to the membership on a volunteer board. Those in this class predominantly participate in meetings and decision making. Compared to the other groups, they are also relatively often entrusted with the organization of activities (e.g., organizing meetings, courses, or fundraising activities; setting up a local volunteer program), administrative tasks (e.g., accounting, keeping volunteer records up-to-date), and educational instruction (e.g., providing training, giving lectures). They are substantially less involved in the provision of medical, social, or psychological assistance. These volunteers have clearly established their position in the Flemish Red Cross; nearly half of them have lengths of service that exceed 10 years. They contribute a low to average number of monthly hours on a fairly regular basis. Moreover, their formal officership coheres with a cultural volunteer profile that is more formalized, falling somewhere between distant and critical.

The third style of volunteering (SOV3) describes a group of reliable coworkers. These volunteers largely are involved in a dependable way (i.e., once to several times a month, 5-12 monthly hours, more than 2 years), but they are not associated with very intensive and long-term forms of involvement. They are also reliable in the sense of identifying moderately to strongly with their volunteer involvement. Characterizing them as coworkers emphasizes their ancillary role as Red Cross volunteers. These volunteers are mainly concerned with medical, social, or psychological assistance and remain underrepresented in executive activities, such as holding a formal office, organizing events, or providing educational instruction. In general, their pattern of participation may best be described as moderately intensive and supportive.

The fourth (SOV4) and fifth (SOV5) styles of volunteering are associated with the center of the Flemish Red Cross. Although the volunteers in these two categories participate in the organization's main activities, they represent a completely different volunteer profile. Based on their most characteristic features, the fourth class (SOV4) of volunteers is identified as service-oriented core volunteers. Among the five volunteer classes, those in this class form the vanguard when it comes to providing medical, social, or psychological assistance. They clearly stand out in these types of services but remain underrepresented in executive functions (e.g., coordinating meetings, decision making, organizing activities). Second, they clearly are core volunteers since they participate in a very frequent (i.e., weekly or more) and time-consuming (i.e., 12 monthly hours at the least) way. Third, their core involvement is reflected in an unconditional to reliable cultural volunteer profile. It 
is striking that, notwithstanding the SOV4 group's prominent position, this volunteer category consists of the largest proportion of relatively new volunteers, those who have been involved for 2 years at most. Only one-third of the group has served the Flemish Red Cross for more than 5 years. Again in contrast with the new images of noncommittal volunteers, the volunteer classification seems to suggest that very demanding commitments are by no means reserved exclusively for the older, established volunteer generation.

The fifth style of volunteering clearly embodies the backbone of the Flemish Red Cross. This group of volunteers are described as the critical key figures. The description signifies that they are critical in a double sense. First, they are of critical importance in determining the success or failure of the volunteer organization. They are truly charged with a number of vital tasks (i.e., board membership, decision making, the organization of activities, administrative work, and fund-raising) that are necessary to guarantee the continued existence of the organization. Furthermore, these jacks-of-all-trades are involved on a long-term and quasi-permanent basis. In this respect, the fifth style of volunteering typically reflects the prototypical and traditional notion of lifelong commitment. Second, and strikingly, their total devotion does not prevent them from representing a critical cultural volunteer profile.

\section{Discussion and Conclusion}

This article considers the debate on transforming modes of volunteer involvement. In the absence of adequate theoretical and methodological tools to address the ongoing discussion, it advances a new analytical framework of styles of volunteering. The article empirically explores the theoretically mapped $\mathrm{SOV}$ construct by means of a representative sample of 652 Flemish Red Cross volunteers.

The existence of five distinct and interpretable styles of Red Cross volunteering suggests that it makes sense to approach the measurement of volunteering in terms of a multidimensional set of cultural and structural indicators that cohere in systematic and varying ways. The analysis arrives at a complex representation of the existing volunteer variety. That representation goes beyond two particular deficiencies in current studies of volunteering.

In comparison with existing monolithic or bifurcated theoretical representations, the empirical mapping first provides a more profound understanding of the multiform nature of volunteering. The findings imply that the popular discourse on traditional and modern volunteerism rests upon an enlargement of certain volunteer characteristics and their effortless allocation to two clear-cut volunteer composites. In practice, the volunteer's culture, intensity of participation, length of service, position, and role are combined in multiple and sometimes intuitively 
contradictory ways. Similar levels of participation (e.g., length of service, intensity of participation) can cohere with highly diverging cultural profiles or volunteer roles. Analogously, the same type of volunteer activity may be performed by volunteers with dissimilar volunteer cultures or levels of participation. The most striking example may be the completely different profiles of the two groups of committee members: the established administrators (SOV2) and the critical key figures (SOV5).

Compared to the other volunteer groups, both groups are significantly more involved in a number of vital volunteer activities (e.g., coordination of meetings, decision making, organization of activities, administrative tasks, training, and lecturing). Despite their comparable job responsibilities, these two groups differ greatly in their intensity of involvement and cultural volunteer profile. For the group of established administrators (SOV2), the involvement seems to be a rather formal matter. The activity includes meetings and decision making; it requires a relatively low to moderate time investment. Among the five groups, these volunteers also take the most distant stance toward the volunteer experience. Critical key figures (SOV5), on the other hand, are involved in an extremely versatile set of activities and demonstrate a quasi-permanent dedication. This unrestricted commitment, however, most likely coheres with a critical cultural profile. Compared to the established administrators (SOV2), the proportion of distant volunteers in SOV5 is remarkably low, and the ratio of unconditional volunteers is rather high.

Also illustrative of the complex interactions at play are the surprising associations with the volunteers' lengths of service. The data indicate that intermittent forms of participation are not synonymous with shortterm or one-off volunteer efforts. On the contrary, even episodic volunteers appear to commit themselves to a particular organization for a relatively long period of time. Furthermore, core involvements are not limited to an established volunteer generation; some of the most active volunteers have joined the Red Cross very recently. Conversely, longterm members are not automatically the most active ones. It becomes clear, however, that a long-term volunteer service is systematically associated with formal board positions.

Second, the measurement approach provides a valuable alternative for the usual unidimensional types of analysis. The multiple interactions that are reflected in the five SOV classification categories point to the added value of envisioning the relationship between different volunteer dimensions, as well as to the benefits of combining structural- and cultural-level analyses. Given that different volunteer characteristics are found to be intertwined parts of the same coordinating volunteering construct, it is crucial for any study of volunteering to take this multidimensionality into account. In contrast, typical research focuses on one single aspect of volunteering (e.g., longevity of service, frequency of volunteering, or motivations for volunteering). This narrow focus con- 
ceals very divergent styles of volunteering. For a more nuanced understanding of this volunteer complexity, it is imperative to clarify the main interactions at work or, at least, to keep them under control. It is hoped that these results are convincing enough to underscore the importance of attuning measurement instruments to a more systematic, comprehensive, multidimensional, and multiform assessment of the nature of volunteering.

Although the new measurement approach has the potential to broaden current knowledge of volunteering, it also has a number of critical limitations. First, although the empirical exploration provides a more refined vocabulary with which to interpret the existing volunteer diversity within the Flemish Red Cross, the results cannot be generalized. Nevertheless, even if one cannot expect to observe identical styles of volunteering in different organizational settings, it is very likely that a similar variety will present itself. Perhaps comparative studies among different organizations might be taken. That could help to overcome a second major weakness: the absence of a dynamic time perspective in this cross-sectional research. Although multiple styles of volunteering are identified, it is not clear whether these styles involve a transformed volunteer reality or whether diversity has always been intrinsic to volunteerism. Furthermore, information about possible transitions among the five volunteer groups is lacking. Could such information enable measurement of different stages of membership (Lois 1999)? For example, is the established administrator category (SOV2) a very specific, rather formalized type of involvement for which these volunteers were explicitly recruited, or did the contribution of members in this class become increasingly focused on formal officership over time? The crosssectional research frame cannot adequately address questions about specific processes and observed style variations. This methodological weakness could be overcome by establishing a standard set of key indicators that are applicable in multiple populations and contexts and that could facilitate longitudinal studies into changing patterns of involvement. A third major weakness is that the measures are designed for an assessment of formal volunteering within a single organization. The measures thus are based on the unlikely assumption that volunteers focus all of their efforts on one organization. The further development of this measurement approach should take into account that the new volunteer tends to shift frequently between organizations and to become involved in unconventional (i.e., less formally organized) ways.

It thus seems that this investigation can serve only as the beginning of a new and more complex measurement strategy for research on the changing nature of volunteering. Through this limited initial empirical exploration, the author nonetheless hopes to have advanced a potential tool for more systematic, comparative, and longitudinal research into this subject. 


\section{Appendix}

\section{Cultural Indicators of Styles of Volunteering}

This appendix presents an overview of the 11 attitudinal scales that were developed to measure four cultural dimensions of the styles of volunteering: (1) the volunteer's perception of the organizational environment, (2) the motives for volunteering, (3) the volunteer's commitment to organization and volunteer work, and (4) the volunteer's tolerance for organizational demands. Per scale, it summarizes the selected evaluation items, the percentage of explained variance in the 11-factor solution, the Cronbach's alpha of the scale, the minimum-maximum range, the mean, and the standard deviation. For each Likert scale constructed, a high score reflects a strong positive attitude toward the latent factor.

\section{Group 1: The Volunteer's Perception of Organizational Environment}

Importance Attached to the Mission of the Organization

The volunteers' evaluation of the mission of the organization is measured by means of a scale of four Likert items with five response categories (applies completely to my situation, applies rather well to my situation, neutral, applies rather badly to my situation, isn't applicable to my situation at all). The scale accounts for 3.69 percent of explained variance in the 11-factor solution. It has a Cronbach's alpha of .70, a minimum-maximum range of $1-5$, a mean equal to 3.24 , and a standard deviation of 0.96 .

1. What appealed to me most were the fundamental principles the organization stands for.

2. I felt challenged by the courses of action the Red Cross undertakes.

3. The Red Cross plays an important role in our society and I wanted to be part of it by volunteering.

4. I joined the Red Cross because I'm interested in the international collaboration within the Red Cross movement.

\section{Perceived Level of Bureaucracy}

The perceived level of bureaucracy is measured by means of a semantic differential consisting of seven seven-point continua between two polar terms. The scale accounts for 35.2 percent of explained variance in the 11-factor solution. It has a Cronbach's alpha of .80, a minimummaximum range of $1-7$, a mean equal to 3.17 , and a standard deviation of 1.05 .

What comes spontaneously to your mind when thinking about the Red Cross in general?

1. Up-to-date to old-fashioned

2. Acting to thinking 


\section{Social Service Review}

3. Accessible to inaccessible

4. Efficient to inefficient

5. Coherent to incoherent

6. Flexible to inflexible

7. Transparent to nontransparent

\section{Group 2: Motives for Volunteering}

Recognition through Volunteering

The importance that the volunteer attaches to recognition through volunteering is measured by means of a scale of six Likert items with five response categories (very important, rather important, neutral, not very important, not at all important). The scale accounts for 10.37 percent of explained variance in the 11-factor solution. It has a Cronbach's alpha of .78, a minimum-maximum range of $1-5$, a mean equal to 2.83 , and a standard deviation of 0.86 .

I'm volunteering with the Red Cross

1. Because it gives prestige and a well-respected position in society

2. Because this kind of work gives me the feeling that I'm needed, that I mean something to society

3. Because my direct environment thinks very highly of volunteer work

4. Because here I can find the satisfaction and the appreciation I can't find in my job

5. To belong somewhere, to be part of an important whole

6. Because the Red Cross as an organization is well appreciated by society

\section{Satisfaction with Volunteering}

The importance that the volunteer attaches to satisfaction through volunteering is measured by means of a scale of six Likert items with five response categories (very important, rather important, neutral, not very important, not at all important). The scale accounts for 12.05 percent of explained variance in the 11-factor solution. It has a Cronbach's alpha of .78, a minimum-maximum range of $1.33-5$, a mean equal to 4.01, and a standard deviation of 0.69 .

I'm volunteering with the Red Cross

1. Because I have had very good experiences with this kind of volunteer work

2. Because of the good atmosphere in the group of volunteers

3. Because I really feel at home in the Red Cross

4. Because of the social contacts one has as a volunteer, because it's a good way of making friends

5. Because I feel good about myself doing it

6. Because I see it as a hobby, a relaxing way of spending time; because I like to do it 


\section{Self-Development through Volunteering}

The importance that the volunteer attaches to self-development through volunteering is measured by means of a scale of five Likert items with five response categories (very important, rather important, neutral, not very important, not at all important). The scale accounts for 8.69 percent of explained variance in the 11-factor solution. It has a Cronbach's alpha of .72, a minimum-maximum range of $1-5$, a mean equal to 3.66 , and a standard deviation of 0.77 .

I'm volunteering with the Red Cross

1. To do something about my own education and development

2. Because this kind of work always remains a challenge to me

3. Because it changes my perspective on things; it broadens my view on life

4. Because I get to know my stronger and weaker sides

5. To learn new skills that can be useful in my current or future profession

\section{Group 3: The Volunteer's Commitment to Organization and Volunteer Work \\ Loyalty}

The volunteer's degree of loyalty is measured by means of a scale of six Likert items with five response categories (completely agree, rather agree, neutral, rather disagree, completely disagree). The scale accounts for 6.67 percent of explained variance in the 11-factor solution. It has a Cronbach's alpha of .77, a minimum-maximum range of $1-5$, a mean equal to 3.65, and a standard deviation of 0.77 .

1. As a volunteer, I use every means necessary to ensure the continued existence of the Red Cross.

2. If I see other Red Cross volunteers, I feel strongly related to them.

3. When a Red Cross volunteer appears in the media, I'm proud of being a Red Cross volunteer myself.

4. It is important to make clear to other volunteers that they should adhere to what the Red Cross expects of them.

5. I like other people to know I'm a Red Cross volunteer.

6. I always try to convince other people to volunteer with the Red Cross.

Devotion

The volunteer's degree of devotion is measured by means of a semantic differential consisting of three seven-point continua between two polar terms. The scale accounts for 5.5 percent of explained variance in the 11-factor solution. It has a Cronbach's alpha of .67, a minimum-maximum range of $1.67-7$, a mean equal to 5.78 , and a standard deviation of 1.05 .

How would you describe yourself as a volunteer? 
1. I do what I want to do./I do what I'm asked to do.

2. I commit myself on certain terms./I commit myself unconditionally.

3. I sometimes neglect my obligations./I live up to my obligations.

\section{Choosiness}

The volunteer's degree of choosiness is measured by means of a scale of five Likert items with five response categories (completely agree, rather agree, neutral, rather disagree, completely disagree). The scale accounts for 2.6 percent of explained variance in the 11-factor solution. It has a Cronbach's alpha of .62, a minimum-maximum range of $1-5$, a mean equal to 3.15 , and a standard deviation of 0.79 .

1. I won't participate in certain activities. Not every kind of work is meant for me.

2. The Red Cross can't expect me to do things I'm not interested in. After all, there is no charge.

3. I consciously limit my engagement, otherwise there will be no end to it.

4. Imposing certain tasks on me would be a reason for me to quit volunteering.

5. I usually choose tasks that interest me. Whether or not the organization benefits from it is of minor importance to me.

Preference for a Low-Level Commitment

The volunteer's preference for a low-level commitment is measured by means of a semantic differential consisting of six seven-point continua between two polar terms. The scale accounts for 3.2 percent of explained variance in the 11-factor solution. It has a Cronbach's alpha of .62, a minimum-maximum range of $1-6.7$, a mean equal to 3.67 , and a standard deviation of 0.91 .

There are many different sorts of volunteer work and everybody has a different way to do it. If you had to start over again, what kind of volunteer work would you take up? In other words, what would be the ideal volunteer work?

1. A long term project/A short term activity

2. A lot of responsibility/Little responsibility

3. Often/One single time

4. For an indefinite period/For a definite period

5. A lot of responsibility, getting involved in something/Few obligations, easy to call it off

6. Taking up different assignments/Taking up a specific job or function

\section{Group 4: The Volunteer's Tolerance toward Organizational Demands}

Tolerance toward Training Demands

The volunteer's tolerance of training demands is measured by means of a scale of five Likert items with five response categories (completely 
acceptable, rather acceptable, neutral, rather unacceptable, completely unacceptable). The scale accounts for 7.4 percent of explained variance in the 11-factor solution. It has a Cronbach's alpha of .71, a minimummaximum range of $1.25-5$, a mean equal to 4.40 , and a standard deviation of 0.68 .

The Red Cross is allowed to

1. Demand you go through a trial period first

2. Demand you take training courses

3. Demand you take an examination before receiving a certificate of attended courses

4. Demand you take a refresher course on a regular basis

5. In order to offer a quality service, preservice and on-the-job training are acceptable

Tolerance toward Rules concerning the Intensity of Commitment

The volunteer's tolerance toward rules concerning the intensity of commitment is measured by means of a scale of four Likert items with five response categories (completely agree, rather agree, neutral, rather disagree, completely disagree). The scale accounts for 4.71 percent of explained variance in the 11-factor solution. It has a Cronbach's alpha of .69 , a minimum-maximum range of $1-4.75$, a mean equal to 2.13, and a standard deviation of 0.87 .

The Red Cross is allowed to

1. Determine a minimum period for you to be a volunteer

2. Determine how often you should take part in an activity

3. Tell you when you should participate

4. Determine how long you have to work on each project

\section{References}

AAPOR (American Association for Public Opinion Research). 2005. Standard Definitions: Final Dispositions of Case Codes and Outcome Rates for Surveys. 3rd ed. Lenexa, KS: AAPOR. Aldenderfer, Mark S., and Roger K. Blashfield. 1984. Cluster Analysis. Quantitative Applications in the Social Sciences, no. 07-044. London: Sage.

Anheier, Helmut K., and Lester M. Salamon. 1999. "Volunteering in Cross-National Perspective: Initial Comparisons." Law and Contemporary Problems 62 (4): 43-65.

Barker, David G. 1993. "Values and Volunteering." 10-31 in Volunteering in Europe: Opportunities and Challenges for the 90s, edited by Justin Davis Smith. Berkhamsted: Volunteer Centre UK.

Beck, Ulrich. 1997. "Kinder der Freiheit: Wider das Lamento über den Werteverfall." 9-33 in Kinder der Freiheit, edited by Ulrich Beck. Frankfurt am Main: Suhrkamp.

Beher, Karin, Reinhard Liebig, and Thomas Rauschenbach. 2000. Strukturwandel des Ehrenamts: Gemeinwohlorientierung im Modernisierungsprozess. Weinheim: Juventa.

Bennett, W. Lance. 1998. "The Uncivic Culture: Communication, Identity, and the Rise of Lifestyle Politics." Political Science and Politics 31 (4): 741-61.

Brömme, Norbert, and Hermann Strasser. 2001. "Gespaltene Bürgergesellschaft? Die Ungleichen Folgen des Strukturwandels von Engagement und Partizipation.” Aus Politik und Zeitgeschichte B25-26: 6-14.

Cnaan, Ram A., and Laura Amrofell. 1994. "Mapping Volunteer Activity." Nonprofit and Voluntary Sector Quarterly 23 (4): 335-51.

Cnaan, Ram A., and Femida Handy. 2005. "Towards Understanding Episodic Volunteer- 
ing." Vrijwillige Inzet Onderzocht: Wetenschappelijk Tijdschrift voor Onderzoek naar Vrijwilligerswerk 2 (1): 29-35.

Cnaan, Ram A., Femida Handy, and Margaret Wadsworth. 1996. "Defining Who Is a Volunteer: Conceptual and Empirical Considerations." Nonprofit and Voluntary Sector Quarterly 25 (3): 364-83.

Curtis, James E., Douglas E. Baer, and Edward G. Grabb. 2001. "Nations of Joiners: Explaining Voluntary Association Membership in Democratic Societies." American Sociological Review 66 (6): 783-805.

Dekker, Paul, and Loek Halman. 2003. "Volunteering and Values: An Introduction." 1-18 in The Values of Volunteering: Cross-Cultural Perspectives, edited by Paul Dekker and Loek Halman. New York: Kluwer Academic/Plenum.

De Vaus, David A. 2001. Research Design in Social Research. London: Sage.

Eckstein, Susan. 2001. "Community as Gift-Giving: Collectivistic Roots of Volunteerism." American Sociological Review 66 (6): 829-51.

Everitt, Brian S. 1993. Cluster Analysis. 3rd ed. London: Arnold.

Farmer, Steven M., and Donald B. Fedor. 1999. "Volunteer Participation and Withdrawal: A Psychological Contract Perspective on the Role of Expectations and Organizational Support." Nonprofit Management and Leadership 9 (4): 349-67.

Gaskin, Katharine. 1998. "Vanishing Volunteers: Are Young People Losing Interest in Volunteering?" Voluntary Action 1 (1): 33-43.

Gorsuch, Richard L. 1983. Factor Analysis. Hillsdale, NJ: Lawrence Erlbaum.

Greenacre, Michael J. 1994. "Correspondence Analysis and Its Interpretation." 3-22 in Correspondence Analysis in the Social Sciences: Recent Developments and Applications, edited by Michael J. Greenacre and Jörg Blasius. London: Academic Press.

Grube, Jean A., and Jane A. Piliavin. 2000. "Role Identity, Organizational Experiences, and Volunteer Performance." Personality and Social Psychology Bulletin 26 (9): 1108-19.

Hacket, Anne, and Gerd Mutz. 2002. "Empirische Befunde zum Bürgerschaftlichen Engagement." Aus Politik und Zeitgeschichte B9: 39-46.

Hagenaars, Jacques A. 1993. Loglinear Models with Latent Variables. Quantitative Applications in the Social Sciences, no. 07-094. Newbury Park, CA: Sage.

Hair, Joseph F., Rolph E. Anderson, Ronald L. Tatham, and William C. Black. 1995. Multivariate Data Analysis with Readings. 4th ed. Upper Saddle River, NJ: Prentice-Hall.

Hajnal, Istvan, and Geert Loosveldt. 1998. EDACLUS: Enkele SAS-macros voor Exploratieve Data Analyse met Behulp van Clusteranalyse. Report no. DA/1998-12. Leuven: Katholieke Universiteit Leuven, Departement Sociologie, Afdeling voor Dataverzameling en Analyse.

Hall, Michael H. 2001. "Measurement Issues in Surveys of Giving and Volunteering and Strategies Applied in the Design of Canada's National Survey of Giving, Volunteering and Participating." Nonprofit and Voluntary Sector Quarterly 30 (3): 515-26.

Handy, Femida, Ram A. Cnaan, Jeffrey L. Brudney, Ugo Ascoli, Lucas C. P. M. Meijs, and Shree Ranade. 2000. "Public Perception of 'Who Is a Volunteer': An Examination of the Net-Cost Approach from a Cross-Cultural Perspective." Voluntas: International Journal of Voluntary and Nonprofit Organizations 11 (1): 45-65.

Hustinx, Lesley. 2003. "Reflexive Modernity and Styles of Volunteering: The Case of the Flemish Red Cross Volunteers." PhD diss. Faculteit Sociale Wetenschappen, Katholieke Universiteit Leuven.

Hustinx, Lesley, and Frans Lammertyn. 2003. "Collective and Reflexive Styles of Volunteering: A Sociological Modernization Perspective." Voluntas: International Journal of Voluntary and Nonprofit Organizations 14 (2): 167-87.

. 2004. "The Cultural Bases of Volunteering: Understanding and Predicting Attitudinal Differences between Flemish Red Cross Volunteers." Nonprofit and Voluntary Sector Quarterly 33 (4): 548-84.

Inglehart, Ronald. 2003. "Modernization and Volunteering." 55-70 in The Values of Vol unteering: Cross-Cultural Perspectives, edited by Paul Dekker and Loek Halman. New York: Kluwer Academic/Plenum.

Jakob, Gisela. 1993. Zwischen Dienst und Selbstbezug: Eine Biographieanalytische Untersuchung Ehrenamtlichen Engagements. Opladen: Leske \& Budrich.

Janoski, Thomas, Marc Musick, and John Wilson. 1998. "Being Volunteered? The Impact of Social Participation and Pro-social Attitudes on Volunteering." Sociological Forum 13 (3): 495-19. 
Kennedy, John M., and Brian Vargus. 2001. "Challenges in Survey Research and Their Implications for Philanthropic Studies Research.” Nonprofit and Voluntary Sector Quarterly 30 (3): 483-94.

Kim, Jae-on, and Charles W. Mueller. 1978a. Factor Analysis: Statistical Methods and Practical Issues. London: Sage.

1978b. Introduction to Factor Analysis: What It Is and How to Do It. London: Sage.

Klages, Helmut. 1998. "Engagement und Engagementpotential in Deutschland: Erkenntnisse der Empirischen Forschung." Aus Politik und Zeitgeschichte B38: 29-38.

Kühnlein, Irene. 1998. "Motivlagen, Sinnquellen und Identitätsrelevanz Erwerbsarbeitsunabhängiger Sozialer Tätigkeiten, Teil der Expertise von Heinze, R. G. \& Keupp, H.: Gesellschaftliche Bedeutung von Tätigkeiten ausserhalb der Erwerbsarbeit.' 107-241 in Erwerbstätigkeit und Arbeitslosigkeit in Deutschland-Entwicklung, Ursachen und Massnahmen: Gutachten im Auftrag der Kommission für Zukunftsfragen, edited by Kommission für Zukunftfragen der Freistaaten Bayern und Massnahmen. Bonn: Kommission für Zukunftfragen der Freistaaten Bayern und Massnahmen.

Kühnlein, Irene, and Gerd Mutz. 1999. "Individualisierung und Bürgerschaftliches Engagement in der Tätigkeitsgesellschaft." 291-306 in Perspektiven Gesellschaftlichen Zusammenhalts: Empirische Befunde, Praxiserfahrungen, Messkonzepte, edited by Ernst Kistler, Heinz-Herbert Noll, and Eckhard Priller. Berlin: Sigma.

Lois, Jennifer. 1999. "Socialization to Heroism: Individualism and Collectivism in a Voluntary Search and Rescue Group." Social Psychology Quarterly 62 (2): 117-35.

Macduff, Nancy L. 2004a. Episodic Volunteering: Organizing and Managing the Short-Term Volunteer Program. Walla Walla, WA: MBA.

. 2004b. "The Shrinking Volunteer: Where Have All Those Long Term Service Volunteers Gone?" Paper presented at the Association for Research on Nonprofit Organizations and Voluntary Action annual conference, Los Angeles, November $18-20$.

- 2005. "Societal Change and the Rise of the Episodic Volunteer." 49-61 in Emerging Areas of Volunteering, edited by Jeffrey L. Brudney. ARNOVA Occasional Paper Series 1, no. 2. Indianapolis: Association for Research on Nonprofit Organizations and Voluntary Action.

Maloney, William A., and Grant Jordan. 1997. "The Rise of Protest Business in Britain." 107-24 in Private Groups and Public Life: Social Participation, Voluntary Associations and Political Involvement in Representative Democracies, edited by Jan W. van Deth. London: Routledge.

McCutcheon, Allan L. 1987. Latent Class Analysis. Quantitative Applications in the Social Sciences, no. 07-064. Newbury Park, CA: Sage.

_ 1994. "Latent Logit Models with Polytomous Effects Variables." 353-72 in Latent Variables Analysis: Applications for Developmental Research, edited by Alexander von Eye and Clifford C. Clogg. Thousand Oaks, CA: Sage.

— 1998. "Correspondence Analysis Used Complementary to Latent Class Analysis in Comparative Social Research." 477-88 in Visualization of Categorical Data, edited by Jörg Blasius and Michael L. Greenacre. London: Academic Press.

. 2002. "Basic Concepts and Procedures in Single- and Multiple-Group Latent Class Analysis." $56-88$ in Applied Latent Class Analysis, edited by Jacques A. Hagenaars and Allan L. McCutcheon. Cambridge: Cambridge University Press.

Meijs, Lucas C. P. M., and Esther Hoogstad. 2001. "New Ways of Managing Volunteers: Combining Membership Management and Programme Management." Voluntary Action 3 (3): 41-61.

Milligan, Glenn W. 1996. "Clustering Validation: Results and Implications for Applied Analyses." 341-75 in Clustering and Classification, edited by Phipps Arabie, Lawrence J. Hubert, and Gert de Soete. River Edge, NJ: World Scientific.

Olk, Thomas. 1989. "Vom 'Alten' zum 'Neuen' Ehrenamt: Ehrenamtliches Soziales Engagement Ausserhalb Etablierter Träger.” Blätter der Wohlfahrtspflege 136 (1): 7-10.

O’Neill, Michael. 2001. "Research on Giving and Volunteering: Methodological Considerations." Nonprofit and Voluntary Sector Quarterly 30 (3): 505-14.

Pearce, Jone L. 1993. Volunteers: The Organizational Behavior of Unpaid Workers. London: Routledge.

Penner, Louis A., and Marcia A. Finkelstein. 1998. "Dispositional and Structural Determinants of Volunteerism." Journal of Personality and Social Psychology 74 (2): 525-37. 
Putnam, Robert D. 2000. Bowling Alone: The Collapse and Revival of American Community. New York: Touchstone.

Reed, Paul, and L. Kevin Selbee. 2003. "Do People Who Volunteer Have a Distinctive Ethos? A Canadian Study." 91-110 in The Values of Volunteering: Cross-CulturalPerspectives, edited by Paul Dekker and Loek Halman. New York: Kluwer Academic/Plenum.

Rommel, Ward, Sybille Opdebeeck, Frans Lammertyn, and Maria Bouverne-De Bie. 1997. Vrijwillige Inzet in Vlaanderen: Een Exploratie. Leuven: LUCAS.

Rooney, Patrick, Kathryn Steinberg, and Paul G. Schervisch. 2004. "Methodology Is Destiny: The Effect of Survey Prompts on Reported Levels of Giving and Volunteering." Nonprofit and Voluntary Sector Quarterly 33 (4): 628-54.

Rummel, Rudolph J. 1970. Applied Factor Analysis. Evanston, IL: Northwestern University Press.

Salamon, Lester M., and Helmut K. Anheier. 1998. "Social Origins of Civil Society: Explaining the Nonprofit Sector Cross-Nationally." Voluntas: International Journal of Voluntary and Nonprofit Organizations 9 (3): 213-48.

Salamon, Lester M., and S. Wojciech Sokolowski. 2003. "Institutional Roots of Volunteering: Toward a Macro-Structural Theory of Individual Voluntary Action." 71-90 in The Values of Volunteering: Cross-Cultural Perspectives, edited by Paul Dekker and Loek Halman. New York: Kluwer Academic/Plenum.

SAS Institute. 1999. "The CORRESP Procedure." Chap. 24 in SAS OnlineDoc. Version 8. Cary, NC: SAS Institute.

Schofer, Evan, and Marion Fourcade-Gourinchas. 2001. "The Structural Contexts of Civic Engagement: Voluntary Association Membership in Comparative Perspective." American Sociological Review 66 (6): 806-28.

Sokolowski, S. Wojciech. 1996. "Show Me the Way to the Next Worthy Deed: Towards a Microstructural Theory of Volunteering and Giving." Voluntas: International Journal of Voluntary and Nonprofit Organizations 7 (3): 259-78.

Steinberg, Kathryn S., Patrick M. Rooney, and William Chin. 2002. "Measurement of Volunteering: A Methodological Study Using Indiana as a Test Case." Nonprofit and Voluntary Sector Quarterly 31 (4): 484-501.

Stolle, Dietlind, and Marc Hooghe. 2005. "Inaccurate, Exceptional, One-Sided or Irrelevant? The Debate about the Alleged Decline of Social Capital and Civic Engagement in Western Societies." British Journal of Political Science 35 (1): 149-67.

Sundeen, Richard A. 1990. "Family Life Course Status and Volunteer Behavior: Implications for the Single Parent." Sociological Perspectives 33 (4): 483-500.

Verhoeven, Jozef C., and Leen Dom. 2002. Flemish Eurydice Report 2001: Education Policy and Education Organization in Flanders. Brussels: Education Policy Coordination Division, Education Department, Ministry of the Flemish Community.

Vermunt, Jeroen. 1997. "LEM: A General Program for the Analysis of Categorical Data, Users' Manual." Tilburg University, Tilburg.

Voyé, Liliane. 1995. "Pour revisiter le bénévolat: Propos hétérodoxes." Swiss Sociological Review 21 (2): 317-40.

Wilson, John, and Marc A. Musick. 1997. "Who Cares? Toward an Integrated Theory of Volunteer Work." American Sociological Review 62 (5): 694-713.

- 1999. "Attachment to Volunteering." Sociological Forum 14 (2): 243-72.

Wollebæk, Dag, and Per Selle. 2003. "Generations and Organizational Change." 161-78 in The Values of Volunteering: Cross-Cultural Perspectives, edited by Paul Dekker and Loek Halman. New York: Kluwer Academic/Plenum.

Wuthnow, Robert. 1998. Loose Connections: Joining Together in America's Fragmented Communities. Cambridge, MA: Harvard University Press.

\section{Notes}

The support of research grant G.0159.98 of the Fund for Scientific Research-Flanders (Belgium) is gratefully acknowledged. The author would furthermore like to thank Jaak Billiet for his helpful methodological and statistical advice. She also wishes to thank the anonymous reviewers of this journal for their valuable comments.

1. According to these key informants, certain Red Cross units could be considered as 
clearly traditional in that their volunteers made long-term and intensive commitments, had an older volunteer population, and reproduced traditional gender patterns, whereas other units were more likely to correspond to the newer volunteer profile (i.e., short-term and rather sporadic; younger age cohorts). A comparison of the different units studied, however, is beyond the scope of this article (for a discussion, see Hustinx 2003, 151-92).

2. In Flanders (Belgium), the terms "lower" and "upper" secondary education refer to the old structure of secondary education, organized into two 3-year cycles (a lower cycle and an upper cycle; Verhoeven and Dom 2002, 98). The Red Cross survey data in this article reflect that former structure, which has since been reorganized. All students who obtained the diploma of secondary education have free access to higher education. Higher education institutions in Flanders can be divided into colleges of higher education (hogeschoolonderwijs) and university education. Outside university, one-cycle programs of higher education provide practical training at the graduate level, whereas two-cycle programs of higher education provide education of an academic level (Verhoeven and Dom 2002, 121-44).

3. Owing to the relatively small sample size, it is necessary to introduce a parsimonious selection of variables into the analysis. More generally, it should be kept in mind that developing empirical measures of theoretical concepts inherently implies a reduction of the broader theoretical horizon of meaning (cf. De Vaus 2001, 27).

4. The author attempted to obtain a more dynamic assessment of the course of involvement by including information about the number of interruptions; however, only 14 percent of the respondents reported that their Red Cross involvement was interrupted at least once in the course of their volunteer career.

5. An initial iterated principal factor analysis with an orthogonal (varimax) rotation used squared multiple correlations as prior communality estimates and included 147 evaluation items with a Likert-type response format. The number of factors was determined in this way, and items were deleted if they loaded on multiple factors or had factor loadings lower than .35 . Next, a rotation to a final factor solution was completed involving 57 remaining items and 11 common factors. An oblique (promax) rotation was deployed because the cultural measures can be correlated (for they are part of the same cultural substratum of styles of volunteering). All items had factor loadings greater than .35. A simple structure, in which items have high loadings on one factor only, was obtained.

6 . The analysis used EDACLUS, an SAS-macro for exploratory data analysis by means of cluster analysis (Hajnal and Loosveldt 1998), which is designed to assist in comparing different (hierarchical) clustering methods, determining the number of clusters, visualizing the obtained cluster solution, and evaluating it. To decide upon the number of clusters, four different criteria were inspected: (1) the $R$-square or the proportion of overall variance explained, (2) the pseudo-F statistic, (3) the Cubic Clustering Criterion, and (4) the pseudo- $T^{2}$ statistic. An inspection of these clustering criteria suggests that clustering in the data is rather weak. Moreover, the clustering methods differed with respect to the proposed optimal number of clusters. The author therefore ultimately relied on theoretical considerations about the mixed volunteer reality and searched for an interpretable cluster solution that yielded the most differentiated picture, both to the volunteer attitudes that were used to define the different groups and to a number of external validation variables (related to the behavioral volunteer characteristics and some key social background characteristics).

7. Although it is a standard practice to perform a multivariate analysis of variance of the variables clustered in order to test for the significance of the clusters, finding significant differences does not prove that the clusters actually exist: "Since the groups were obtained from, and can generally be defined by partitions on each variable, the discriminant analysis almost always returns significant results, even from random noise data" (Milligan 1996, 366-67; cf. Aldenderfer and Blashfield 1984, 64-65).

8. In an intermediate step, an identical latent class analysis was performed for the structural indicators of the styles of volunteering only. It resulted in a single multivariate measure that contained five latent classes $\left(L^{2}=43.39 \mathrm{df}=32, p=.0862\right)$. These five patterns of volunteering can broadly be described as: (1) a supportive peripheral pattern: a very infrequent and relatively short-term involvement that requires a low time investment and remains typically limited to the provision of medical, social, or psychological assistance; (2) an administrative intermediate pattern: a fairly regular, timeconsuming, and long-term involvement that is concentrated on the membership on a 


\section{Social Service Review}

volunteer board; (3) a supportive intermediate pattern: a fairly regular, time-consuming, and relatively short-term involvement that remains typically limited to the provision of medical, social, or psychological assistance; (4) a supportive core pattern: a very frequent, time-consuming, and relatively short-term involvement that is focused on the provision of medical, social, or psychological assistance; and (5) an all-around core pattern: a very frequent, time-consuming, and long-term involvement that includes all types of activities and, in particular, a number of key volunteer tasks, such as decision making, the organization of activities, administrative tasks, and educational instruction (Hustinx 2003, 223-32). However, these intermediate results are not deemed to be central to the general argument of this article. A detailed discussion of this initial classification exercise is therefore beyond the scope of this article. Table 2 nonetheless reports the parameter estimates of this initial latent class analysis. It furthermore should be noted that the bivariate association of this five-class variable with the cultural volunteer clusters is statistically significant $\left(\chi^{2}=58.89, \mathrm{df}=12, p<.0001\right)$.

9. Correspondence analysis is used to "find a low-dimensional graphical representation of the rows and columns of a crosstabulation or contingency table. Each row and column is represented by a point in a plot determined from the cell frequencies" (SAS Institute 1999, 947). As is common, here the first two dimensions of this Euclidean space are plotted to observe the associations among the SOV categories (columns) and the structural and cultural SOV components (rows; SAS Institute 1999, 990). Each dimension explains a certain percentage of the total chi-square, which is a measure of the association between the rows and columns of the contingency table (see SAS Institute 1999, 949). 